\title{
Correction to: Completion Thyroidectomy: Revisited a Quarter of a Century Later
}

\author{
Benzon M. Dy, MD', Veljko Strajina, $\mathrm{MD}^{2}$, Michael Tuttle, $\mathrm{MD}^{3}$, and Ashok R. Shaha, $\mathrm{MD}^{3}$ \\ ${ }^{1}$ Mayo Clinic, Breast, Endocrine, Metabolic and GI Surgery, Rochester; ${ }^{2}$ Mayo Clinic, Surgery, Rochester; ${ }^{3}$ Department of \\ Head and Neck Surgery, Memorial Sloan-Kettering Cancer Center, New York
}

\section{CORRECTION TO: ANN SURG ONCOL (2019) 26:694-696 \\ HTTPS://DOI.ORG/10.1245/S10434-018-07102-Z}

In the original article's XML file, Benzon M. Dy's middle initial was tagged incorrectly. The error has been addressed with this correction. 